\title{
Deconstrucciones discursivas en Edipo entre los inkas de César Calvo \\ Discoursive Deconstructions in César Calvo's Edipo entre los inkas
}

\author{
Cristóbal Cardemil Krause \\ Rutgers, The State University of New Jersey \\ crisfcar@gmail.com
}

Edipo entre los inkas (César Calvo, 2001) explora las relaciones entre las tradiciones occidentales y del oriente peruano. Calvo busca demostrar la insuficiencia de la epistemología occidental para explicar la oriental. Este ensayo muestra cómo se relacionan los discursos tratados por Calvo. La obra es compleja, crítica y polisémica en su estructura y tratamiento de la epistemología occidental, aunque presenta la oriental desde una perspectiva con un significante único e inamovible. Esto puede comprenderse como una limitación, pero el esfuerzo general de la obra sirve para fomentar la necesidad de aceptar la diversidad y el respeto entre realidades diferentes.

Palabras clave: epistemología occidental; epistemología indígena andina; crítica poscolonial.

Edipo entre los inkas (César Calvo, 2001) explores connections between the traditions of the Western World and the Peruvian Orient. Calvo tries to demonstrate the inadequacy of Western Epistemology when explaining the Orient. This essay shows how the different discourses Calvo analyzes are related. The work is complex, critical, and polysemic in its structure and treatment of Western Epistemology, but presents the Oriental Epistemology from a perspective with a unique and fixed signifier. This may be considered as a limitation, but the general effort of Calvo's work helps to generate the need to accept diversity and respect among different realities.

Keywords: western epistemology; andean indigenous epistemology; postcoIonial criticism. 
"La verdad no es la verdad sino nuestra verdad".

(Calvo, 482)

En el año 2001, el Congreso de la República del Perú decidió celebrar la vida y obra del recientemente fallecido poeta César Calvo Soriano (19402000) con la publicación de su obra en tres partes Edipo entre los inkas. Estos libros siguen la estructura del ensayo, pese a que en sus páginas se incluye también poesía y narrativa, fotografías de la vida de Calvo y reproducciones de algunas de las obras de su padre, el pintor César Calvo de Araujo. En Edipo entre los inkas César Calvo explora las distintas relaciones existentes entre las tradiciones occidentales y las del oriente peruano, que él comprende como una Amazonía fuertemente influida por el pensamiento andino-inca. Calvo critica e intenta demostrar la insuficiencia de la epistemología occidental para explicar la realidad oriental, que le es extraña ${ }^{1}$. Esto puede entenderse como una deconstrucción del modelo occidental frente a perspectivas diferentes. El presente ensayo busca mostrar el modo en que los distintos discursos tratados por Calvo se relacionan y funcionan entre sí. Para eso, me centraré en distintos aspectos de Edipo entre los inkas, como su estructura y la expresión de distintos discursos y el modo en que Calvo se refiere a las epistemologías occidental y oriental. Este texto se entiende, desde mi enfoque, como una obra compleja, crítica y polisémica en cuanto a su estructura y su tratamiento de la epistemología occidental, pero que presenta, al mismo tiempo, la epistemología oriental desde una perspectiva que trabaja con un significante único e inamovible. Esto puede comprenderse como una limitación con respecto de los objetivos de Calvo. Sin embargo, el esfuerzo general de la obra sirve para establecer la necesidad de enfrentar las distintas epistemologías de un modo distinto, que acepte la diversidad y el respeto necesario en la comprensión de realidades diferentes. Es decir, por medio de buscar una forma de establecer contactos que permitan un diálogo mayor entre ellas -en este caso, a partir del reconocimiento de discursos no hegemónicos, que desafían un discurso impuesto desde la época colonial.

\section{Edipo entre los inkas: Estructura de un texto}

Edipo entre los inkas comienza y termina con la discusión del mito de los indígenas amazónicos awaruna sobre cómo fue que las mujeres aprendieron a parir, a partir de una rata. En un principio, era el hombre el que paría y

\footnotetext{
1 Considerando los distintos usos teóricos que se pueden encontrar en la crítica literaria y cultural de la palabra "oriental", vale la pena insistir en que este término en la obra de Calvo corresponde a la distribución geográfica de la república peruana, en que se diferencian tres áreas específicas: la costa, cuya ciudad principal es Lima; la sierra, cuya ciudad principal es Cusco; y el oriente, la selva o la montaña, cuya ciudad principal es Iquitos. En la tradición cultural peruana, la mayor cantidad de estudios se centran en la costa y la sierra y un cierto antagonismo existente entre ellas. El oriente ha quedado relegado en estudios literarios más amplios: "La marginalidad de la zona de Selva explica la escasez de las manifestaciones literarias que aluden a su problemática y la frecuencia con que caen en el exotismo" (Cornejo Polar 220). Pese a que en la obra de Calvo el término "oriente" y lo "oriental" en ocasiones juegan con la dicotomía "oriente/occidente" de la cual hace referencia Said en Orientalism, entre otros, en este artículo, la referencia al oriente se limita a la diferenciación geográfica ya explicada, y la fuerte relación que Calvo establece entre esta área y el ámbito andino de la sierra.
} 
amamantaba a los recién nacidos. En esta actividad, el hombre solía asesinar a los varones y solo permitía vivir a las hembras. Cuando el hombre descubrió que la mujer había aprendido a parir, renunció y se cortó los pechos, tirándolos luego hacia la mujer, que desde entonces es quien pare y amamanta a los niños. Calvo analiza esta situación, poniendo cuidado en no juzgarla ni interpretarla desde una perspectiva occidental, sino tal como es, evitando usar una mirada esencialista (23-25, 591-94). Lo que busca es establecer una línea clara que lo ponga en un límite navegable entre la manera de comprender el mundo desde una perspectiva occidental y una indígena: una perspectiva liminal que abarca circularmente toda la obra. Sin embargo, la estructura circular no es suficiente para terminar de comprenderla. Hay otros elementos que la hacen sumamente compleja y que exigen verla desde perspectivas que no son lineales ni circulares.

Un primer aspecto es la publicación de distintos libros, que parece responder a la manera en que Calvo refleja sus pensamientos en el papel: "Aquí compruebo que me resulta inevitable seguir los múltiples y súbitos requerimientos de este libro. Debo recomenzar por un comienzo distinto que, simultáneamente, acceda a proseguirse desde un otro libro" (126). Calvo muestra que no siente un control total sobre lo que escribe, y que tampoco cree que deba sentirlo. El rol del autor no es excesivamente fuerte ni se pretende dar la impresión de que no es posible manejar todas las ideas. El texto está dotado de vida propia, es capaz de cambiar de rumbos y de exigir cambios. El recomenzar por otro comienzo, en este caso, no borra el inicial, sino que le añade otra realidad. Edipo entre los inkas se constituye en un texto de muchos comienzos y ningún final claro. Es necesario comenzarlo varias veces, y cada iteración supera y agrega a la otra, logrando un resultado que excede el total del texto.

Otro elemento es el uso de letras, términos y frases en negrillas, que, por contraste, le entrega a esas apariciones un carácter singular, más o menos específico. En algunos casos estas apariciones son rastreables (como el uso de negrillas para ansias y ansiedades -v. 30, 32, 39, 99, en el primer libro), pero no siempre, como cuando marca algunas palabras en idiomas indígenas, algunas preposiciones en el texto, citas, entre otras. Esto hace que exista una consciencia distinta en el acto de lectura, por cuanto el texto parece remitir a otras partes del mismo, no tan solo por sus ideas principales, sino también por aquello que puede esconder estas apariciones (que en algunos momentos son muy corrientes, mientras que en otros desaparecen). Independiente del significado mismo, es innegable que la lectura cambia profundamente, puesto que este uso de negrillas dota al texto de quiebres y cambios en el ritmo y la idea de intensidad del sonido de la lectura. Esto, además, permite la lectura del texto de manera vertical, aparte de una horizontal.

En su ensayo, Calvo remite a distintos autores de novelas, poesía o carta, pero no siempre explicita las referencias que realiza, lo que, en un ámbito legal occidental es considerado plagio, un problema de derechos de autor. Calvo incluye pequeños trozos de textos publicados en distintos momentos, en ocasiones con "algunos pequeños cambios" (459). Hay pequeños casos como con partes de la obra Los Imperios del Sol (1996) de Guillermo Thorndike (1940-2009), y poemas de Isidro Kunturi (o Isidro Condori, un nombre asociado con la obra 
de Calvo, al mismo tiempo que motivo de dudas y posibles alegatos de robos de obras por su parte, v. Lévano) y del músico Manongo Mujica (n. 1950). El caso principal, sin embargo, es el de la inclusión desordenada de partes de las novelas de temática indígena El Cantar de Agapito Robles (1977) y La tumba del relámpago (1979) de Manuel Scorza (1928-1983), bajo el nombre de Vida y milagros de Santa Maca de Chayacán. Calvo se sorprende del resultado de esta inclusión, que se extiende por sobre 100 páginas del segundo libro de Edipo entre los inkas, afirmando que el recorte y reunión de los distintos capítulos, "una vez escogidos y separados de sus mundo-tiempos originales para instituirse dentro del cauce de otro mundo-tiempo ( $y$ pese a no haber sido alterados en 'su ser' textual sino solo en 'su siendo' contextual al orden de otra secuencia), den como resultado, verdaderamente, la espiral de una obra inédita formada por elipsis ya editadas particular, distinta y anteriormente" (341). Ciertos términos resultan claves para comprender uno de los objetivos de Calvo a través de Edipo entre los inkas, que es el de la alteración, o el de hacer consciente la existencia de una alteración para comprender la relación entre la realidad y el tiempo. En este caso, la alteración de las novelas de Scorza, a la vez que evidentemente intertextual -pues se establece un diálogo entre la obra de Scorza y el texto de Calvo, y entre el texto de Calvo y la reestructuración de las novelas de Scorza, y entre las novelas de Scorza y la reestructuración de las novelas de Scorza-, destruye conceptos específicos de la legalidad occidental, como son los derechos de autor o el mismo concepto de autoría. Pese a que son reconocidos como textos de Scorza, y como una "posible" obra inédita de Scorza, el trabajo fue realizado por Calvo, lo que hace complejo el establecimiento de un autor específico para la nueva novela espiral.

Independiente de las problemáticas legales a las que todas estas situaciones dan pie, los textos incluidos dotan al texto de una significación mayor. Para Calvo, esto sería una respuesta a la rigidez con que la sociedad occidental ha establecido el manejo de las obras literarias: "En el caso de los libros publicados oralmente como 'La Iliada' y 'La Odisea' y como la poesía prehispánica, el hecho de su transmisión formaba parte del acto creativo que hoy sustituye nuestra escritura frígida, y la co-participación de los escuchas en la re-escritura creadora de las obras continúa siendo irremplazable" (594). De esta manera, el trabajo realizado en Edipo entre los inkas estaría volviendo -rompiendo los esquemas de espacio y tiempo- a un momento en que el arte no era tan solo comercio. Un momento que recuerda los inicios de la cultura occidental, al mismo tiempo que la cultura anterior a los españoles.

Un último aspecto importante en la estructura de la obra es el compendio de 696 términos de nombres de lenguas y grupos indígenas destruidos por la llegada de los conquistadores a la Amazonía, que cubre treinta y cuatro páginas del libro tercero. Este quiebre con la estructura del texto busca entregar otra forma de entender el proceso de destrucción que comenzó con la llegada de los españoles, sus armas y sus enfermedades a América. Sin embargo, es una denuncia que va más allá de la Amazonía, ya que es fácilmente extensible a otros grupos que sufrieron con la obra colonizadora europea:

Lo que he consignado en las siguientes páginas, no son palabras. Son nombres de naciones e idiomas exterminados en aras de la civilización occidental. A lo largo de 
mis andares por las entreveradas patrias de la Amazonía natal, solo he podido recopilar 696. En cada letra hay niños, hay ancianos, hay mujeres y varones reclamándonos, recordándonos que ellos fundaron la existencia del mundo en nuestra selva. Millones de inocentes victimados (494).

Con esta enumeración, que es incompleta y que está limitada por los conocimientos que Calvo ha adquirido a lo largo de su experiencia, nos deja entrever que es un trabajo que quizás no se alcance a completar, o que no pueda ser completado. Este quiebre estructural se vuelve una letanía, una queja adolorida por la pérdida que causó la invasión europea. Pese a que el ataque a la llegada de los europeos es un tema constante en Edipo entre los inkas, esta incorporación le añade un valor y una significación mayores al tema tratado.

El último aspecto en relación a los quiebres estructurales en Edipo entre los inkas son los capítulos referidos a Nurinarda. En estos se desarrolla una ficción que nace a partir de las reflexiones de Calvo en el ensayo en general. Los textos de Nurinarda se reparten en siete de los últimos diez capítulos del ensayo, y el primer capítulo en que aparece lleva el título de "Primera intromisión de Nurinarda". Tanto Nurinarda como la inclusión de la obra de Scorza y la de poetas, están, a fin de cuentas, también atacando los modelos en que corrientemente se comprenden los géneros literarios en la cultura de Occidente. Los quiebres, de esta manera, van más allá de estructuras lineales, circulares o multivocales, e influyen en el modo general en que se comprende la obra de Calvo, los temas que trata, las obras con que se relaciona y las perspectivas que toma a partir de todos estos elementos.

Todo lo que ha sido descrito respecto de la estructura del texto puede iluminarse de una mejor manera según lo que Gilles Deleuze y Félix Guattari denominan escritura rizomática. Según explican, el rizoma es la expresión de la literatura como un ensamblaje, es decir, como un texto que funciona como muchos textos y que en ese sentido se vuelve múltiple. Pese a que eso hace que el texto en sí pierda un carácter ideológico específico y de significación última, le da, al mismo tiempo, una capacidad inagotable de significación, con posibilidades inacabables de nuevas interconexiones y reconstituciones (93-4). Edipo entre los inkas no duda en criticar la epistemología occidental y, a partir de esa perspectiva, se puede decir que su ideología es antioccidental. Sin embargo, es algo inadecuado definir una ideología desde una perspectiva opositora nada más -la cual, por lo demás, no es totalmente adecuada para entender la postura de Calvo, que busca evitar caer en la misma situación negadora que propone la forma de comprender el mundo de Occidente. Lo central es que se establecen características que dotan de una extensión mayor a un texto que, en sus tres libros, está limitado a poco más de 600 páginas. Siguiendo con Deleuze y Guattari, se puede profundizar la relación entre el ensayo de Calvo y la metáfora del rizoma: "A rhizome ceaselessly establishes connections between semiotic chains, organizations of power, and circumstances relative to the arts, sciences, and social struggles. A semiotic chain is like a tuber agglomerating very diverse acts, not only linguistic, but also perceptive, mimetic, gestural, and cognitive" (97). Los distintos elementos mencionados -inclusión de textos narrativos propios o 
ajenos, el uso de negrillas, la letanía de nombres amazónicos- son los que dotan al texto de esta versatilidad, de esta capacidad múltiple, y los que también posibilitan las conexiones múltiples tanto dentro del texto como de elementos contextuales, aparentes o no.

\section{César Calvo en Edipo entre los inkas, o "yo no somos uno"}

Thomas Docherty caracteriza lo posmoderno como un ataque a la idea de identidad, a la idea de Ser en el tiempo, en el espacio. Es decir, un ataque al Ser a través de la heterogeneidad: "Postmodern figures are always differing, not just from other characters, but also from their putative 'selves'" (140). Pese a que puede existir una noción de identidad, se ve siempre puesta en duda por el entorno y sus múltiples posibilidades, que lleva al personaje a estar siempre en un proceso de desdoblamiento, que no acaba, sino que se mantiene difiriendo de cualquier nueva identidad que se adopte: hay una diferencia constante. Aun cuando esto hace que el sujeto, por sí mismo, no tenga una significación ética o política específica, en la caracterización posmoderna, por medio de esa misma negación, reaparece la posibilidad de tratar temas políticos y éticos a través de la lectura, realizada por quien lee, puesto que es arrastrado fuera de su propia noción de identidad, centrada y estable, a una noción de marginalidad, que lo convierte, de este modo, en un disidente (146).

La diferencia constante a la que se refiere Docherty se encuentra en la escritura de Calvo de una manera más bien directa, a partir de opciones gramaticales discursivas que toma la voz del ensayo. Así, este texto, que se comprende a partir de la voz siempre cambiante y reactualizada y reactualizable de Calvo -"resalté que un libro es un proceso de creación, producción que comienza mucho antes de ser concebido y vuelve a comenzar cada vez que es leído" (594)-, está dentro de un marco de escritura posmoderna. En la obra, Calvo se inscribe en distintas tradiciones, en las que se mueve de manera más o menos cómoda. De esta manera, nos encontramos con un narrador que puede trabajar a partir del discurso psicoanalítico: "A nosOtros, diferentes en los meridianos aspectos cruciales que despliega el psicoanálisis pariendo desde su base al lenguaje, nos resulta natural que muchas palabras tengan un significado en castellano y otro en psicoanalítico" (76), en que la tradición epistemológica occidental se ve poco transgredida. Incluso se la puede encontrar en un ámbito más heterogéneo, como se puede ver por cómo continúa esta cita pocas líneas después: "el psicoanálisis viene siendo creador y creación de un lenguaje propio, pasible de crecer, emparejarse, procrear y morir, existiendo en castellano dentro de la realidad keshwa de un subconsciente mayor" (76). Acá se relaciona lo occidental con lo indígena por medio del lenguaje y la aceptación de las diferentes influencias en un sujeto -en este caso occidental e indígena. Calvo encuentra, de este modo, una manera de relacionar las distintas tradiciones por medio de un lenguaje en común, que no niega a partir de su ejercicio, sino que demuestra el modo en que se complementan y funcionan en conjunto, aunque en el ámbito subconsciente.

0 , también, en otros casos la voz narrativa puede realizar cambios violentos y sin mediación de ningún tipo, porque se comprende que la identidad del narrador no es una, sino múltiple, porque son múltiples también sus experiencias: 
El día en que nosotros los conquistadores españoles de hace quinientos años derruimos el gigantesco falo de granito que nosotros los Inkas de hace quinientos años hubimos erigido en lo alto del Qosqo, ese mismo día la obra del pintor Andrés Molina entró en la clandestinidad. Lo que para los Inkas era orgullo, poder límpido y símbolo de procreación equiparable al Puma sagrado con cuya figura fue edificada la ciudad del Qosqo, para los europeos representaba lo que ellos mismos denominaban "sus vergüenzas". Dos maneras opuestas de caminar por la vida conviven desde entonces en contienda (419).

En este caso la diferencia que caracteriza la voz narrativa incluso se traslada en el tiempo, imaginándose conquistadora al mismo tiempo que inca hace quinientos años, para luego volver a establecerse narrativamente en un tiempo "presente", en donde puede explicar que lo que sucedió hace cinco siglos fue un choque de epistemologías que no se ha solucionado hasta el día de hoy -lo que es, a fin de cuentas, el argumento central de Edipo entre los inkas. Incluso si se reconoce que las distintas maneras de ver el mundo pueden en ocasiones, en algunos sujetos, trabajar en conjunto, todavía están caminando en forma paralela, y no hermanadas. Las diferencias epistemológicas se comprenden como una disputa, un choque de fuerzas que no está en armonía.

También nos podemos encontrar con la voz amazónica: "Cuando los amazónicos decimos 'creo que ya me voy a morir', la palabra 'voy' tiene la misma connotación inequívoca del verbo en movimiento que posee para todos los andinos. Ir hacia la muerte, entrar en la muerte, estar cerca de la muerte. Pero morir (así, en castellano), no" (421). Acá, sin embargo, existe una diferencia notoria. En este caso, al ser mencionados los incas, no se ve la noción de pelea. De esta forma, la voz narrativa establece una alianza entre los diferentes grupos indígenas. Pero no se debe olvidar que tanto la construcción de la posible identidad de un sicólogo como la de un conquistador, un peruano, un andino o un amazónico, también son plausibles de ser interpretadas, leídas, a partir de la diferencia del sujeto-lector al que se refiere Docherty, lo que complica, en ciertos aspectos, los constantes cambios de posicionamiento de la voz narrativa de Calvo: esta voz narrativa está en pos, siempre, del encuentro con lo otro, que es aquello que no dice, a lo que no se refiere, pese a todo.

\section{Deconstruyendo a Freud}

César Calvo parece estar respondiendo a la forma de entender el mundo común en Europa desde hace siglos. Walter Mignolo trae a la luz una frase de Francis Bacon que, a su juicio, explica la manera en que Europa se relaciona con poblaciones y gobiernos en el resto del planeta -lo que Mignolo llama el "sistema-mundial moderno" (modern-world system): "there can be no others", en referencia a la Historia, la Poesía y la Filosofía (todas en mayúsculas). Esta idea, que establece la centralidad de Europa (desde la perspectiva europea), define una relación directa entre un espacio geopolítico -el occidente- y eliminó la posibilidad de considerar legítimos conocimientos que vinieran desde otras localidades (227). Es esta idea la que critica Calvo al referirse al psicoanálisis 
freudiano. Él no piensa que Freud no tuviera razón cuando se refería a su cultura, pero ve limitaciones en su modelo cuando se intenta explicar otras tradiciones. Para Calvo, la teoría freudiana es una herramienta occidental, y como tal se le deben entender sus límites. Es incapaz de abarcar todo, porque no todo puede ser abarcable. La lucha que Calvo emprende contra Freud es más bien contra sus seguidores, quienes intentan entender distintas tradiciones epistemológicas desde perspectivas específicamente occidentales:

Algunos discípulos empeñados en interpretar el pasado andino transfieren criterios como si fueran medios de disección inherentes a las producciones literarias, en el supuesto mecánico e iluso de que basta exhumarlas instrumentando métodos pluridisciplinarios, para acceder al secreto de su "verdadero significado" y luego explicarlas "con su contexto histórico integral" desde el presente de su "perspectiva psicoanalítica" (109).

El problema, luego, no es el psicoanálisis, sino la intención de universalizarlo, lo que, para Calvo, es una reproducción de los modelos de conquista. Son sus discípulos los que producen el problema, al buscar, infructuosa pero obsesivamente, forzar sus interpretaciones en realidades que les son ajenas, buscando encontrar elementos esenciales comunes en maneras que no son adecuadas, puesto que olvidan o eliminan factores que los hacen diferentes y específicos.

Los reparos de Calvo ante la interpretación y ordenamiento del oriente indígena peruano por parte de occidente, mediante el psicoanálisis, pueden ser extrapolados a la actividad completa de la epistemología occidental sobre otras epistemologías en el mundo. El problema de la epistemología occidental sería la incapacidad de poner en diálogo de una manera válida -y no hegemónica- las diferencias epistemológicas de otros grupos culturales en el mundo, más específicamente, de la población indígena en la sierra y selva del Perú: "los textos andinos devienen desquiciados por el analfabetismo (de los analistas anglo-castellanos) respecto del idioma keshwa (de sus forzados psicoanalisandos). Más que de un convicto desconocimiento, se trata de un confeso no reconocimiento del Runasimi en tanto que interlocutor vigente, válido, digno de ser tenido en cuenta como tal" (109-10). Se reconoce que quienes vienen en pos de comprender y explicar la cultura indígena son conocedores de sus propias tradiciones y sus ideas, pero los denuncia porque ese conocimiento no puede ser igualado con lo que se necesita para explicar lo indígena en sí mismo. El uso de palabras como "analfabetismo" y "desconocimiento" deja en claro que el problema se centra en la incapacidad de comprender otras maneras de ver el mundo. También se puede comprender que la mirada de los "psicoanalistas" es orgullosa y obtusa, lo que la limita en su relación con gente que tiene otra manera de comprender el mundo².

2 Es posible profundizar aún más en este aspecto si se toma en cuenta las múltiples ocasiones en que se discuten temas referentes a la manera en que se discute el deseo y la sexualidad en la obra de Calvo. Estos temas son presentados desde perspectivas que desafían la comprensión comúnmente aceptada por el psicoanálisis freudiano acerca de estos términos. Se puede ver, con mayor profundidad, por ejemplo, la manera en que el 
La solución de Calvo para este conflicto es la de establecer un contacto que haga eficaz la comunicación entre las distintas epistemologías. Esto, a través de un proceso que no solo involucre el respeto por las diferencias que hacen de cada experiencia algo específico, sino también la comprensión de aquellas, y el esfuerzo por buscar soluciones conjuntas a problemas que nacen del choque forzado entre las distintas realidades y formas de comprender el mundo:

¿Seguiremos forzando la ilusión de una "síntesis" que niega, de palabra, tanto la "tesis" de los conquistados como la "antítesis" de los conquistadores, pero que prolonga, de hecho, la realidad colonial? ¿O seremos los co-hacedores de un destino que se reclama inevitablemente respetuoso de la diversidad, en el cual se re-establezcan "debidamente" los derechos de los antiguos y de los nuevos peruanos $y$, por fin, se equivalgan todas nuestras herencias antagónicas? (385)

Las respuestas a estas preguntas son respondidas en el texto de Calvo. Primero, haciendo notar que es necesario dejar de forzar esa ilusión que de hecho prolongaría la realidad colonial -por medio de asumir que la hegemonía de occidente sobre la población indígena del Perú, los está llevando o intentando llevar a un proceso de aculturación que los haga entrar por la fuerza a un sentido de modernidad que ellos no comparten. Segundo, en el restablecimiento de los derechos de los antiguos y nuevos peruanos por medio del respeto a la diversidad, que dejen de lado el antagonismo que ha sido generado por el proceso de la historia.

El procedimiento propuesto por Calvo es similar al que propone Boaventura de Sousa Santos, es decir, un proceso de traducción, que permite "criar inteligibilidade recíproca entre as experiências do mundo, tanto as disponíveis como as possíveis" (30). El trabajo de traducción, según lo define Santos, funciona a través de la reunión y bajo la influencia de distintos tipos de conocimientos y prácticas: "A tradução entre saberes assume a forma de uma hermenêutica diatópica. Consiste no trabalho de interpretação entre duas ou mais culturas com vista a identificar preocupações isomórficas entre elas e as diferentes respostas que fornecem para elas" (31). Con esta hermenéutica diatópica se comprende cada cultura como incompleta y capaz de enriquecerse mediante el contacto con otras, a través del diálogo y la confrontación. Esto no significa que, en el proceso, los involucrados deban convertirse en relativistas, sino que puedan apreciar y valorar diferencias entre culturas. Un trabajo de traducción exitoso comienza de un elemento de interés común a las diferentes culturas, e intenta encontrar puntos de convergencia para ellas (33). En este caso, el trabajo de traducción sería entre la cultura occidental y la oriental peruana, según lo afirmado por Calvo.

mito fundador al que Calvo hace referencia al principio de la cosmogonía indígena, y cómo eso transgrede la relación entre los sexos en el análisis de mitos de Freud. También, existe una nueva estructura en la manera en que se trata la figura de Maca, en la rescritura de la obra de Scorza. Sin embargo, estos temas pueden ser objeto de un estudio mayor, que supera el foco del presente artículo. 


\section{Una (¿)nueva(?) visión del oriente}

Todas las características observadas hasta ahora en Edipo entre los inkas pueden comprenderse como formando parte de una obra compleja -que escapa a concepciones lineales a la hora de la lectura-, crítica -en particular de los modelos epistemológicos occidentales- y polisémica -puesto que cada elemento presente en el texto debe ser necesariamente observado y comprendido desde una diversidad de perspectivas, a partir de sus relaciones internas y externas. Sin embargo, a partir de todo lo discutido, existe un problema que no deja de ser menor, y es el hecho de que, a lo largo del texto, pareciera que existiera, constantemente, una forma de comprender lo Occidental como si fuera algo particular, específico, que puede ser entendido unívoca e indiscutiblemente, en contraste con otra realidad que se ve del mismo modo, que es la oriental. Mientras tanto, lo polisémico aparece en el espacio que queda entre lo occidental y lo oriental. Vale preguntarse si es que esto produce un problema mayor en el argumento específico presentado por Calvo. Más allá, como se verá a continuación, el proceso de deconstrucción de la mirada occidental, a través de la crítica del psicoanálisis freudiano, no existe al observar el oriente. Se puede decir que, en ese sentido, el oriente indígena peruano parece incluso más monolítico que el occidente.

Edipo entre los inkas propone visiones específicas tanto del mundo incaico como del amazónico. Ambas tradiciones están ligadas tanto por su historia pre-hispánica como por la que siguió luego de la llegada de los españoles. Esto, principalmente, porque existe una coincidencia de orígenes: el camino desde Asia: "Entre los mochica-chimú, los chibcha, los arawak y los mayakiché, más que semejanza de lenguas y parecido racial, hay una mismidad de procedencias; exactamente todo lo contrario a la unanimidad de procederes que nos legó por fuerza y en herencia reciente el Virrey Tánatos" (96). Calvo da a todos los pueblos americanos este origen, estableciendo una realidad y experiencia comunes para todos ellos con relación a occidente. Esto es incluso más claro cuando se refiere a todos estos pueblos indígenas como compartiendo la realidad en la forma de un "nosotros", en contraste con el "yo" individualista del europeo.

La llegada de los españoles terminó con la organización social y comunal de los incas, al mismo tiempo que los condenó a vivir en condiciones alienadas y peores a las cuales estaban acostumbrados. Calvo describe esta llegada y sus resultados negativos para los grupos indígenas del Tahuantinsuyo con el término quechua Pacha Kutii, o Pachacuti, que hace referencia a un gran cambio, a una situación social o histórica que cambia la vida específica de un grupo. Pachacuti se relaciona con una revolución, un desastre, un gran acontecimiento o suceso, con un cataclismo: "el Pacha Kutii expresa un acontecimiento comunal que pertenece a lo que modifica: todo mundo-tiempo personal (se) comprende (en) el de los demás, de cuyas permanencias toma cuerpo (y a las cuales incorpora) su inacabable perentoreidad" (381). El pachacuti cambia tanto a los individuos como a los grupos, lo que se puede observar en la discusión en que Calvo afirma que un occidental, cuando un indígena quechua dice, en castellano, "eso pasó en 1534", debiera entender, en quechua, "Esto es lo que ya es (o "desde") 1534 nos ha estado pasando aquí" (386). Para los incas, el pachacuti todavía tiene repercusiones, 
ya que los efectos devastadores de la llegada de los españoles todavía son sentidos. Así, el trabajo de traducción se vuelve central, no tan solo desde la perspectiva de estilo, sino también porque se deja en claro que no existe una comprensión de que un suceso tan antiguo todavía se presente como algo fresco en la mente de quienes sufrieron las mayores pérdidas materiales y como individuos.

Calvo discrepa con quienes atacan su modelo de entender el mundo andino, que se basa marcadamente en lo que se ha establecido por medio de investigaciones arqueológicas o por lo descrito por quienes son más cercanos a la realidad de los incas: "Resulta extraño que para buscar una versión más andina (tal como afirma el Psicorracismo Anónimo) se ningunee los testimonios del Inka Garcilaso y se dé crédito a falsarios" (125). Es decir, sus conocimientos, si bien bastante extendidos por sus propias experiencias, están basados también en una tradición que se remonta a los años iniciales de la dominación española en el Perú. Eso se puede ver también en la adopción de las ideas de Thorndike acerca de la vida de los indígenas antes de que llegaran los españoles:

Hombres y mujeres comunes se agrupaban en ayllus o comunidades que compartían el mismo espíritu de una laguna o montaña tutelar. No se conocía la moneda. La riqueza se distribuía entre los ayllus de acuerdo al antiguo principio andino de la reciprocidad. A nadie se le ocurría acumularla. Tal como nacían, los hombres estaban destinados a morir. No había hambre. No tenían una palabra que expresara el concepto del dinero (460-1).

En estas pocas líneas, aparecen aspectos que se pueden considerar centrales en un estudio formal de una sociedad. En un primer momento aparece la relación mística del humano con el medio ambiente, es decir, un concepto de religión que en este caso está conectado fuertemente con el agua y la geografía de los espacios centrales que ocupaba el Tahuantinsuyo. También al principio aparece la estructuración social del grupo estudiado, en este caso, la agrupación por comunidades o ayllus. Luego aparecen aspectos de la economía de la cultura, y aquí ocurre que no tienen un sistema monetario desarrollado, porque, como se vive en comunidades y en reciprocidad entre los habitantes, no existe el hambre ni la necesidad de tener algo que se asemeje al dinero. Se puede asumir que, como la idea de acumular individualmente no existía, al igual que no existía el hambre, el pueblo fuera también sano y viviera en un estado cercano a la satisfacción, ya que las necesidades básicas no solo estaban cubiertas, sino también garantizadas por el sistema comunal. Es una visión utópica y digna de la vida prehispánica. Sin embargo, también es una visión esencialista y que reproduce los modelos de análisis europeos -la negación de los relatos y crónicas de conquistadores, la estética del romanticismo-, lo que debilita su argumento.

Respecto de su visión del mundo amazónico, Calvo se basa en las tradiciones orales y sus propias experiencias en esos territorios. En ese sentido, no duda en dar valor de verdad a aquello que los nativos de esa zona consideran como suyo: "La verdad no es la verdad sino nuestra verdad, exclama 
con voz dura y oscura el maestro Ino Moxo" (482). Esto, que puede ser visto como un acercamiento a una comprensión relativa del medio y de la realidad, es, a la vez, una expresión de respeto por las creencias de otros. Más allá de las diversas alusiones que hace Calvo al mundo amazónico, hay una insistencia mayor en relacionar esa tradición a la del mundo andino, dotando al mundo amazónico de características específicas a este, incluida la espera de los indígenas amazónicos de la vuelta del inca, lo que ha sido llamado "mesianismo" o "milenarismo" andino: "Ellos escriben en sus cuerpos y se leen mientras cumplen los turnos de una drástica vigilia que ya dura quinientos años y que únicamente con una contraorden expresa del joven Manko Inka podrá finalizar" (139). De este modo, se introduce una realidad alterna a la visión moderna de nación en el Perú, que se puede comprender como una relación mayor entre los pueblos indígenas, a partir de su mitología y forma de comprender el mundo, lo que no es criticado como las perspectivas occidentales, quizás porque han sido forzadas al silencio durante un largo tiempo.

\section{Edipo entre los inkas como un llamado a la reevaluación del mundo indígena}

Si nos atenemos a lo que he discutido acerca de la obra de Calvo, como un texto que puede entenderse como desde una estética de la posmodernidad, tanto en su estructura como en su crítica a la tradición occidental, entonces el modo en que describe y se atiene a la realidad indígena del Perú es inconsistente con su método. Sin embargo, la obra de Calvo no pierde valor en cuanto a lo que discute y busca: el que hasta cierto punto las reflexiones de Calvo muestren ser incapaces de asumir totalmente la perspectiva del oriente peruano que intenta representar, no implica que Edipo entre los inkas pierda legitimidad en cuanto a acciones de importancia que se deben tomar en el tratamiento de culturas que no comparten en muchos aspectos las creencias y puntos de vista que se defienden, en distintos grados, en el mundo occidental. Pese a que el tratamiento de la realidad indígena tiende más a mostrarla como monovalente y constante, su inclusión dentro de un texto como Edipo entre los inkas no le quita sino que le añade valor, puesto que se debe buscar, también, un método de traducción que permita una reevaluación del mundo indígena en el Perú.

El objetivo de cambiar el tratamiento del mundo indígena por parte de Calvo puede entenderse desde la perspectiva de la "colonialidad" (coloniality) planteada por Walter Mignolo, y que se comprende como la respuesta ante una realidad colonial, que niega las instancias de expresión de quienes están sometidos a ella (228). La colonialidad es el lugar de enunciación de la diferencia que existe entre los espacios silenciados y la hegemonía de los elementos coloniales. Mignolo Ilama a esto la "diferencia colonial" (colonial difference) (229-30). En especial, la actividad que nace de la colonialidad, es la de la crítica y el establecimiento de un punto de vista que difiera de la epistemología occidental: "The limit of Western philosophy is the border where the colonial difference emerges, making visible the variety of local histories that Western thought, from the Right and from the Left, hid and suppressed" (234). Ante esto, la colonialidad haría patente la necesidad de aceptar que el conjunto de ideas éticas, políticas y epistemológicas de 
occidente, ante la presencia de otras epistemologías, no son suficientes para entender y explicar el mundo, sin importar si son visiones desde el espectro político de la izquierda o de la derecha (252).

Calvo, en este sentido, habría trabajado desde aquel límite marcado por Mignolo, intentando realizar el trabajo de la colonialidad, lo que lo sitúa en el centro de un debate que intenta generar un conocimiento efectivo y particular de un espacio que está bajo la hegemonía cultural de occidente. Esto refuerza la idea de realizar un trabajo de traducción como el que plantea Santos, y le entrega un mayor valor a la obra de Calvo en cuanto pertenece a una tradición cultural que intenta establecer un punto de vista particular que difiere notoriamente de lo que se afirma desde los distintos centros de poder occidentales, sean nacionales, como en el caso de Lima, o foráneos, como el de la tradición europea. El esfuerzo de Calvo se centra, luego, en abrir las diferentes perspectivas, en pos de un mayor respeto por la diversidad, que vaya más allá del discurso, pero que también se demuestre en acciones concretas. Es decir, y como lo muestra la siguiente cita, el esfuerzo de Calvo es por unir a partir de la diferencia, más que el de separar a partir de ellas:

con el descubrimiento de América, comienza verdaderamente la creación del Nuevo Mundo para beneficio de toda la humanidad, no solo de los europeos. Y no lo podemos llamar de otro modo, porque se abrió un nuevo ( $y$ formidable y trágico) escenario de la dimensión histórica del hombre, y con él comenzó propiamente la Historia Universal que desde los griegos no había sido sino estrictamente regional (103).

A fin de cuentas, el discurso postmoderno de Calvo, la búsqueda de las distintas voces que aparecen a lo largo de Edipo entre los inkas, la rabia y la nostalgia que se hacen evidentes en distintas partes de la obra, la admiración que siente por las culturas indígenas prehispánicas, no se cierran a una realidad que, pese a que no es ideal, debe enfrentarse, no solo a través de la mirada de lo andino y oriental, sino también con una mirada que acceda al mundo con una serie diferente de reglas, que les permita desarrollarse a partir del respeto y el entendimiento de los distintos actores con sus diferentes puntos de vista. Edipo entre los inkas se puede describir, luego, como una obra que está buscando redefinir el modo de interacción entre distintas culturas, algo que, según afirma el texto, no ha sido logrado desde la llegada de los españoles a América.

\section{Obras citadas}

Calvo Soriano, César. Edipo entre los inkas: El sexo y otros dioses. Libro primero. Lima: Fondo Editorial del Congreso del Perú, 2001. Impreso. Edipo entre los inkas: Freud (y otros poetas) en el antiguo Perú de nuestros días. Libro segundo. Lima: Fondo Editorial del Congreso del Perú, 2001. Impreso.

Edipo entre los inkas: Edipo entre los inkas. Libro tercero. Lima: Fondo Editorial del Congreso del Perú, 2001. Impreso. 
Cornejo Polar, Antonio y Jorge Cornejo Polar. Literatura peruana siglo XVI a siglo XX. Lima: Centro de estudios literarios "Antonio Cornejo Polar", 2000. Impreso.

Deleuze, Gilles and Félix Guattari. "Rhizome." 1980. Trans. B. Massumi. Postmodern Literary Theory: An Anthology. Ed. Niall Lucy. Malden, Massachusetts: Blackwell Publishers, 2000. 92-120. Excerpt from $A$ Thousand Plateaus: Capitalism and Schizophrenia. 1980. Trans. B. Massumi. Minneapolis: University of Minnessotta Press, 1987. Impreso.

Docherty, Thomas. "The Ethics of Alterity." 1996. Postmodern Literary Theory: An Anthology. Ed. Niall Lucy. Malden, Massachusetts: Blackwell Publishers, 2000. 140-8. Excerpt from "The Ethics of Alterity: Postmodern Character." Alterities: Criticism, History, Representation. Oxford: Clarendon Press, 1996. 36-68. Impreso.

Lévano, César. "Los años y los sueños". La primera. 19 de agosto de 2007. www.diariolaprimeraperu.com. NP. 19 de agosto de 2007. Web. 7 de mayo de 2011.

Mignolo, Walter D. "The Geopolitics of Knowledge and the Colonial Difference." South Atlantic Quarterly 101, No. 1 (winter 2002): 57-96. Rpt. in Coloniality at Large: Latin America and the Postcolonial Debate. Ed. Mabel Moraña, Enrique Dussel and Carlos A. Jáuregui. Durham: Duke University Press, 2008. 225-58. Impreso.

Said, Edward. Orientalism. 1978. New York: Vintage Books, 1979. Impreso.

Santos, Boaventura de Sousa. "Para uma sociologia das ausências e uma sociologia das emergencias." Published in Boaventura de Sousa Santos (org.) Conhecimento prudente para uma vida decente: "Um discurso sobre as ciencias" Revisitado. Porto: Afrontamento, 2003. Centro de Estudios Sociais. Rutgers University, New Brunswick, NJ. 15 October 2007. <http://www.ces.uc.pt /bss/documentos/sociologia_das_ausenci as.pdf $>$. 